\title{
Recovery of hypothalamic-pituitary-adrenal function after intermittent high-dose prednisolone and cytotoxic chemotherapy
}

\author{
KENNETH S. WILSON \\ B.Sc., M.R.C.P.
GRAHAM P. LIDGARD*
Ph.D.
Christina E. Gray $\dagger$
Ph.D.
Alistair C. Parker
Ph.D., M.R.C.P.

\begin{abstract}
The Royal Infirmary and Regional Hormone Laboratory*, Edinburgh, and the Stobhill General Hospital, Glasgow $\dagger$
\end{abstract}

\begin{abstract}
Summary
Hypothalamic/pituitary and adrenal (HPA) function was assessed in ten patients who received intermittent high-dose prednisolone and cytotoxic chemotherapy for 5-40 months. Standard insulin hypoglycaemia (IHT), thyrotrophin-releasing hormone and tetracosactrin tests were performed $36 \mathrm{hr}$ after the last dose of prednisolone and subsequently 10 days -52 weeks after completion of all chemotherapy.

In the first tests there was evidence of impaired hypothalamic-pituitary function judged by peak adrenocorticotrophic hormone (ACTH), growth hormone (GH) and thyrotrophin (TSH) responses, and corresponding plasma corticosteroid responses were sub-normal in five patients. In the final IHTs, seven patients had persistently subnormal ACTH responses but all the corresponding plasma corticosteroid responses returned to normal. Mean peak corticosteroid responses to insulin and tetracosactrin and peak GH responses were significantly greater than in the first tests. Such chemotherapy regimens may have prolonged effects on hypothalamic/pituitary function but the demonstration of normal corticosteroid responses to hypoglycaemia and tetracosactrin indicates that these patients' stress responses will be normal as early as $\mathbf{1 0}$ days after treatment is stopped.
\end{abstract}

\section{Introduction}

Intermittent high-dose prednisolone and cytotoxic drug therapy is now widely used in the treatment of myeloma (Alexanian et al., 1969) and Hodgkin's disease (De Vita, Serpick and Carbone, 1970) with improvement in remission rates. Such treatment regimens have recently been shown to cause suppression of the hypothalamic-pituitary-

Correspondence: Dr K. S. Wilson, Saskatoon Cancer Clinic, University Hospital, Saskatoon, Saskatchewan, Canada S7N OW8. adrenal (HPA) axis (Wilson et al., 1976; Naysmith et al., 1976). Although this occurs particularly at the hypothalamic-pituitary level, secondary adrenal suppression has also been demonstrated. Full recovery of HPA function on cessation of continuous and intermittent corticosteroid therapy may take many months (Graber et al., 1965; Malone, Grant and Percy-Robb, 1970) and in this time additional steroid therapy may be required during severe intercurrent illness.

The authors report the results of hypothalamicpituitary and adrenal function tests at different times after completion of treatment in patients with myeloma or lymphoma who received intermittent high-dose prednisolone and cytotoxic chemotherapy. Combined insulin-induced hypoglycaemia and thyrotrophin-releasing hormone tests followed by intravenous tetracosactrin tests were performed twice in each patient, the first series $36 \mathrm{hr}$ after treatment courses and the second series 10 days-52 weeks after completion of all chemotherapy to observe initially the degree of suppression and subsequent extent of recovery of HPA function.

Patients studied

\section{Myeloma patients}

Seven patients with multiple myeloma were studied (see Table 1). Patients 2 and 5 had IgA myeloma and patients 1, 3, 4, 6 and 7 had the IgG type. The mean duration of therapy was 20 months (range 6-40). Patient 2 received 4-day courses of prednisolone $(120 \mathrm{mg} /$ day $)$ and the remainder received 7-day courses (40-80 $\mathrm{mg} /$ day) along with melphalan (6-10 mg/day). Before commencing chemotherapy, patients $2,3,6$ and 7 received radiotherapy to the lumbar spine.

\section{Lymphoma patients}

Three patients with lymphoma were studied. 
TABLE 1. Peak plasma corticosteroid, ACTH and GH responses during two insulin hypoglycaemia tests, peak plasma TSH

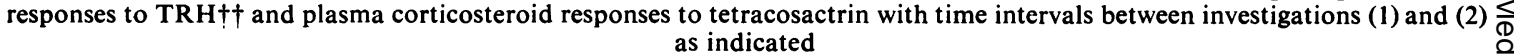

\begin{tabular}{|c|c|c|c|c|c|c|c|c|c|c|c|c|c|}
\hline \multirow[b]{2}{*}{ Patient } & \multirow{2}{*}{$\begin{array}{c}\text { Treatment } \\
\text { duration } \\
\text { (months) }\end{array}$} & \multirow{2}{*}{$\begin{array}{l}\text { No. of } \\
\text { courses }\end{array}$} & \multirow{2}{*}{$\begin{array}{c}\text { Interval } \\
\text { between } \\
\text { tests }\end{array}$} & \multicolumn{2}{|c|}{$\begin{array}{l}\text { Corticosteroids } \\
(\mathrm{nmol} / \mathrm{l})\end{array}$} & \multicolumn{2}{|c|}{$\begin{array}{c}\mathrm{ACTH} \\
(\mathrm{ng} / \mathrm{l})\end{array}$} & \multicolumn{2}{|c|}{$\begin{array}{l}\mathrm{GH}^{* *} \\
(\mathrm{mu} / \mathrm{l})\end{array}$} & \multicolumn{2}{|c|}{$\begin{array}{l}\mathrm{TSH} \dagger \\
(\mathrm{mu} / \mathrm{l})\end{array}$} & \multicolumn{2}{|c|}{$\begin{array}{c}\text { Corticosteroids } \\
\text { after } \\
\text { tetracosactrin }\end{array}$} \\
\hline & & & & (1) & (2) & (1) & (2) & (1) & (2) & (1) & (2) & (1) & (2) \\
\hline $1 \mathrm{~F}$ & 12 & 9 & 10 days & 520 & 740 & 13 & 27 & $10 \cdot 7$ & $62 \cdot 3$ & $<0.66$ & 0.77 & 650 & 785 \\
\hline $2 \mathrm{~F}$ & 6 & 4 & 3 weeks & 310 & 665 & 84 & 91 & $18 \cdot 0$ & $48 \cdot 0$ & $9 \cdot 5$ & $9 \cdot 0$ & 415 & 880 \\
\hline $3 \mathrm{~F}$ & 16 & 12 & 7 weeks & 430 & 555 & $<15$ & 28 & $8 \cdot 6$ & $39 \cdot 8$ & $4 \cdot 9$ & $5 \cdot 7$ & 500 & 700 \\
\hline $4 \mathrm{M}$ & 14 & 10 & 13 weeks & 415 & 690 & 89 & 58 & $49 \cdot 7$ & $36 \cdot 7$ & $19 \cdot 7$ & $6 \cdot 3$ & 645 & 880 \\
\hline $5 \mathrm{M}$ & 23 & 19 & 48 weeks & 645 & 740 & 86 & 168 & $11 \cdot 9$ & $37 \cdot 0$ & $7 \cdot 0$ & $9 \cdot 3$ & 780 & 875 \\
\hline $6 \mathrm{M}$ & 28 & 18 & 52 weeks & 655 & 835 & $<26$ & 43 & $10 \cdot 1$ & $10 \cdot 5$ & $3 \cdot 3$ & $3 \cdot 1$ & 765 & 905 \\
\hline $7 \mathrm{M}$ & 40 & 19 & 52 weeks & 600 & 815 & 105 & 120 & $6 \cdot 3$ & $36 \cdot 3$ & $6 \cdot 6$ & $11 \cdot 6$ & 550 & 780 \\
\hline $8 \mathrm{~F}$ & 5 & 5 & 40 weeks & 635 & 760 & $<25$ & 79 & $14 \cdot 8$ & $70 \cdot 7$ & $15 \cdot 5$ & $8 \cdot 2$ & 640 & 1035 \\
\hline $9 \mathrm{M}$ & 6 & 5 & 48 weeks & 745 & 785 & $<25$ & 302 & $31 \cdot 0$ & $74 \cdot 3$ & $2 \cdot 0$ & $5 \cdot 8$ & 790 & 950 \\
\hline $10 \mathrm{M}$ & 6 & 6 & 52 weeks & 325 & 995 & 20 & 26 & $53 \cdot 0$ & $>69.0$ & $7 \cdot 2$ & $7 \cdot 5$ & 405 & 1010 \\
\hline
\end{tabular}

* ACTH =adrenocorticotrophic hormone; ${ }^{* *} \mathrm{GH}=$ growth hormone; $\dagger \mathrm{TSH}=$ thyroid-stimulating hormone; $\dagger \dagger \mathrm{TRH}=$ thyrotrophin-releasing hormone.

Patients 9 and 10 with Hodgkin's disease received intermittent chemotherapy with mustine, procarbazine and vinblastine in standard doses together with prednisolore $40 \mathrm{mg} /$ day in 14-day courses. Patient 8 with non-Hodgkin's lymphoma received prednisolone $40 \mathrm{mg} /$ day in 14-day courses along with procarbazine, vincristine and cyclophosphamide. The mean duration of therapy was 6 months (range 5-6).

\section{Methods}

Standard insulin-induced hypoglycaemia tests, IHT, (Landon, Wynn and James, 1963) were performed $36 \mathrm{hr}$ after the last dose of prednisolone and at varying intervals from 10 days to 1 year after all treatment had been stopped. Plasma samples were obtained at zero, 20, 30 and 60 min after the intravenous administration of soluble insulin $0 \cdot 15$ units/ $\mathrm{kg}$ body weight and $200 \mu \mathrm{g}$ of thyrotrophin-releasing hormone (TRH). Plasma-corticosteroids were measured by fluorimetry (MRC Report, 1971), corticotrophin (ACTH) by radio-immunoassay after extraction of plasma with porous glass, using natural human ACTH for iodination and standardization (Ratcliffe and Edwards, 1971), thyrotrophin (TSH) and growth-hormone (GH) by radioimmunoassay (Toft et al., 1973; Hunter, 1972). Plasmaglucose was determined by an automated glucose-oxidase method (Morley, Dawson and Marks, 1968). After the 60-min plasma samples were taken, $250 \mu \mathrm{g}$ tetracosactrin was given intravenously and samples taken at +30 and +60 min thereafter to determine plasma-corticosteroids.

At the times of assessment of HPA function there was no evidence of primary or secondary disease of the pituitary and adrenal glands. Skuil X-rays showed normal pituitary fossae and abdominal films showed no adrenal calcification. No patient's cे serum contained antibodies against the steroid- 음 producing cells of the adrenal cortex.

Normal response criteria in the IHT were as follows: for corticosteroids (Irvine and Barnes, 1972) $\varnothing$ peak values $>550 \mathrm{nmol} / 1$; for ACTH (Staub et at 3 1973) a peak value $>109 \mathrm{ng} / \mathrm{l}$ with an increment $\Phi$ above basal $>80 \mathrm{ng} / \mathrm{l}$; for GH (Hartog, Gaafer anf Fraser, 1964) a peak value $>18 \mathrm{mu} . / \mathrm{l}$; for TSH (Hall et al., 1972) after intravenous TRH, a pes. value of $>5.9 \mathrm{mu}$./ 1 in men and $6.8 \mathrm{mu}$./ in women. After insulin, plasma-glucose concentrations fell to $<2 \cdot 2 \mathrm{nmol} / 1(40 \mathrm{mg} / \mathrm{dl})$ in all patients. Normal o plasma corticosteroids after tetracosactrin (Angeli $\stackrel{0}{\circ}$ et al., 1973) are $>445 \mathrm{nmol} / 1(16 \cdot 1 \mu \mathrm{g} / \mathrm{dl})$.

\section{Results \\ Myeloma patients}

Plasma ACTH responses were sub-normal in all patients in the first IHT and sub-normal in all except patients 5 and 7 in the second IHT indicating hypothalamic-pituitary suppression (see Table 1). Corresponding plasma corticosteroid responses were sub-normal in patients $1,2,3$ and 4 in the first IHT but were all within the normal range in the second tests. Plasma corticosteroid responses to tetraco- 옥 sactrin were normal in all patients except in the first $\supset$ test in patient 2 , indicating definite adrenal suppression in this patient; in the second tetracosactrin $N$ tests, plasma corticosteroid responses were greater than in the first tests, suggesting that a degree of adrenal suppression had occurred in the remainder. $N$

Plasma GH responses were sub-normal in the first 2 IHT in patients $1,3,4,5$ and 6 and returned to 0 normal in the second tests in all except patient 6.

Plasma TSH responses were sub-normal in patients $\stackrel{?}{+}$ 1,3 and 6 in the first TRH test and were persistently 
sub-normal in these patients in the second test. However, thyroid function judged clinically and by total serum thyroxine, serum triiodothyronine and effective thyroxine ratio remained normal in these patients.

\section{Lymphoma patients}

Plasma ACTH responses were markedly subnormal in the first IHT in these patients, indicating hypothalamic-pituitary suppression and only one patient (9) subsequently attained a normal response. Plasma corticosteroid responses were normal except in the first IHT in patient 10 and the following tetracosactrin test in this patient was also subnormal, indicating adrenal suppression in addition. The remainder of the tetracosactrin tests were normal, but the plasma corticosteroid responses were greater in the second tests.

Plasma GH responses were normal in all but the first IHT in patient 8.

Plasma TSH responses in both TRH tests in patient 9 were sub-normal but the patient remained clinically and biochemically euthyroid. The TSH responses in patients 8 and 10 were normal.

\section{Discussion}

The reduction of corticosteroid therapy in systemic non-malignant disease is largely limited by the presence or lack of an exacerbation of the underlying disease; thereafter, the degree of suppression of HPA function becomes the most important factor. Abrupt cessation of steroid therapy in myeloma and lymphoma does not apparently adversely influence disease activity and has not been associated with the development of acute features of pituitary-adrenal insufficiency (Wilson et al., 1976; Naysmith et al., 1976) but the demonstration of abnormal plasma corticosteroid responses to insulin-induced hypoglycaemia indicates the likely requirement for additional steroid therapy during serious intercurrent illness in these patients.

The pattern of recovery of HPA function in such patients has not been previously reported and differs from that observed in patients who experience longterm suppression as a result of either Cushing's syndrome or continuous steroid therapy. In these patients (Graber et al., 1965), plasma ACTH levels were sub-normal for 1 month and in most cases were elevated for 2-5 months before returning to normal; plasma corticosteroid levels did not return to normal until 6 months and the corticosteroid responses to exogenous ACTH did not return to normal until at least 9 months.

We observed no consistent pattern of basal plasma ACTH levels on cessation of intermittent steroid therapy. Three patients had low basal ACTH levels at least 40 weeks later and no patients were found to have elevated basal levels. Although no significant difference was observed between the peak ACTH responses during the two IHTs $(P>0 \cdot 1)$ ACTH was undetectable in four patients undergoing their first IHT but was detectable in all ten patients during the later tests. Seven patients had impaired plasma ACTH responses during IHTs performed up to 1 year later, indicating prolonged partial anterior pituitary suppression.

Further evidence of impaired anterior pituitary function was found in the patients who had persistently sub-normal plasma TSH responses to exogenous TRH many months after stopping treatment. Depression of such plasma TSH responses has been observed following chemotherapy courses (Naysmith et al., 1976) and in patients on long-term steroid therapy (Otsuki, Dakoda and Baba, 1973) but the time-course and pattern of recovery has not been reported.

Prolonged suppression of $\mathrm{GH}$ secretion during insulin hypoglycaemia was observed in only one patient although it was frequently suppressed immediately after treatment was stopped in the myeloma patients who received at least nine courses. Peak growth hormone levels during the second IHTs were significantly higher than during the first $(P<0.01)$. GH secretion during IHTs performed immediately after treatment courses in thirteen lymphoma patients was normal (Thalassinos et al., 1976) and in patients receiving continuous steroid therapy, GH responses were sub-normal (Irvine and Barnes, 1972). However, the time course of GH secretion during hypoglycaemia may be too slow for its total output to be assessed in $60 \mathrm{~min}$ (Daly et al., 1974) and this could influence conclusions on the effect of drugs on $\mathrm{GH}$ release during short IHTs.

Most important, however, from the clinical standpoint was the demonstration of normal peak plasma corticosteroid responses in the second IHTs in all the patients, indicating normal stress responses as early as 10 days after cessation of intermittent steroid therapy. A significant difference was observed between the peak corticosteroid responses in the two IHTs $(P<0.01)$. Normal corticosteroid responses to tetracosactrin correlated well with the responses during the second IHTs, and a highly significant difference between responses in the tetracosactrin tests was apparent $(P<0 \cdot 001)$. These results suggest that assessment of the functional integrity of the HPA axis in patients who have completed high-dose intermittent steroid and cytotoxic drug therapy should be deferred until the second week off treatment when it is likely that normal corticosteroid responses to insulin and tetracosactrin will be demonstrable. 


\section{Acknowledgments}

We wish to thank Dr James Innes for permission to study patients under his care; Dr J. G. Ratcliffe for his advice in the preparation of this report; Professor L. G. Whitby for the plasma corticosteroid and glucose determinations.

\section{References}

Alexanian, R., Haut, A., Khan, A.U., lane, M., McKelvey, E.M., Migliore, P.J., Stuckey, W.J. \& WILSON, H.E.J. (1969) Treatment for multiple myeloma. Journal of the American Medical Association, 208, 1680.

Angeli, A., Frajria, R., Bocuzzi, G., Bisbocci, D. \& Ceresa, F. (1973) Paradoxical response of plasma cortisol to pulse intravenous injection of synthetic corticotrophin and dibutyryl cyclic adenosine $3^{\prime}, 5^{\prime}$-monophosphate in adult panhypopituitarism. Acta endocrinologica, 74, 250.

Daly, J.R., Fletcher, M.R., Glass, D., Chambers, D.J., BITENSKY, L. \& CHAYEN, J. (1974) Comparison of effects of long-term corticotrophin and corticosteroid treatment on responses of plasma growth hormone, ACTH and corticosteroid to hypoglycaemia. British Medical Journal, 2, 521.

De Vita, V.T.Jr, Serpick, A.A. \& Carbone, P.P. (1970) Combination chemotherapy in the treatment of advanced Hodgkin's disease. Annals of Internal Medicine, 73, 881.

Graber, A.L., Ney, R.L., Nicholson, W.E., Island, D.P. \& LIDDLE, G.W. (1965) Natural history of pituitary-adrenal recovery following long-term suppression with corticosteroids. Journal of Clinical Endocrinology, and Metabolism, 25, 11.

Hall, R., Ormston, B.J., Besser, G.M., CRyer, R.J. \& MCKENDRICK, M. (1972) The thyrotrophin-releasing hormonetest in diseases of the pituitary and hypothalamus. Lancet, i, 759.

Hartog, M., GaAfer, M.A. \& Fraser, R. (1964) Effect of corticosteroids on serum growth hormone. Lancet, ii, 376.

HuNTER, W.M. (1972) Techniques Radioimmunologiques. Seminaire Hôpital Saint-Antoine, Paris, 385. L'Institut National de la Santé et de la Recherche Médicale, Boulogne.

IRVINE, W.J. \& BARNES, E.W. (1972) Adrenocortical insufficiency. Journal of Clinical Endocrinology and Metabolism, 1, 549.
LANDON, J., WyNN, V. \& JAmes, V.H.T. (1963) The adrenocortical response to insulin-induced hypoglycaemia. Journal of Endocrinology, 27, 183.

Malone, D.N.S., Grant, I.W.B. \& PerCy-Robb, I.W. (1970) $c$ Hypothalamo-pituitary-adrenal frunction in asthmatic patients receiving long-term corticosteroid therapy. Lancet, $\stackrel{\vec{P}}{+}$ ii, 733.

MRC Working Party RePort (1971) Recommended method for the determination of plasma corticosteroids. British Medical Journal, 2, 310.

MORley, G., DAwson, A. \& MARKs, V. (1968) Manual and $\mathbb{\complement}$ autoanalyser methods for measuring blood glucose using guaiacum and glucose oxidase. Proceedings of the Asso- 0 ciation of Clinical Biochemists, 5, 42.

Naysmith, A., Hancock, B.W., Cullen, D.R., Richmond, J. \& WILDE, C.E. (1976) Pituitary function in patients receiving intermittent cytotoxic and corticosteroid therapy for malignant lymphoma. Lancet, i, 715.

Otsuki, M., Dakoda, M. \& BABA, S. (1973) Influence of glucocorticoids on TRF-induced TRH response in man. Journal of Clinical Endocrinology, 36, 95.

RATCLIFFE, J.G. \& EDwaRds, C.R.W. (1971) The extraction of of adrenocorticotrophin and arginine vasopressin from $\odot$ human plasma by porous glass. In: Radio-immunoassay $\underset{ }{ }$ Methods (Ed. by K. E. Kirkham and W. M. Hunter), cr p. 502. E. \& S. Livingstone, Edinburgh.

Staub, J.J., Jenkins, J.S., Ratcliffe, J.G. \& Landon, J. (1973) Comparison of corticotrophin and corticosteroid response to lysine vasopressin, insulin and pyrogen in man. British Medical Journal, 1, 267.

Thalassinos, N.C., Tountas, N., Thomopoulos, D雨 DemerTZI, H., IKKos, D. \& GaRdikas, C.D. (1976) Ф Hypothalamic/pituitary/adrenal function in patients of chemotherapy. Lancet, $\mathbf{i}, 1238$.

Toft, A.D., Seth, J., Kirkham, K.E., Marshall, A. IRVINE, W.J. (1973) Assessment of in vitro thyroid function tests in 100 consecutive patients referred to a thyroid clinic. Journal of Clinical Endocrinology, 2, 127.

Wilson, K.S., Gray, C.E., Cameron, E.H.D., Seth, J. \& PARKER, A.C. (1976) Hypothalamic/pituitary/adrenal function in patients treated with intermittent high-dose prednisolone and cytotoxic chemotherapy. Lancet, i, 610 . 